\title{
Thapsigargin increases apoptotic cell death in human hepatoma BEL-7404 cells ${ }^{1}$
}

\author{
GU JUN*, He LIU**, TAO FU**, YonghuA XU**2 \\ * Laboratory of Molecular Biology, Naval Medical Research \\ Institute, Shanghai 200433, China \\ **Laboratory of Cellular and Molecular Oncology, Shang- \\ hai Institute of Cell Biology, Chinese Academy of Sciences, \\ Shanghai 200031, China
}

\section{ABSTRACT}

Effects of thapsigargin, an inhibitor of $\mathrm{Ca}^{2+}$-ATPase in surface of endoplasmic reticulum, on apoptotic cell death were studied in human hepatoma cells of BEL-7404 cell line by using both flow cytometry and electron microscopy. Propidium iodide staining and flow cytometry revealed that in the serum-free condition, thapsigargin increased the rate of apoptosis of BEL- 7404 ceils in a dose-dependent manner. Prolongation of the period of serum-free condition enhanced the apoptosis induced by thapsigaxgin treatment. Morphological observation with electron microscope further demonstrated that chromatin condensation and fragmentation, apoptotic bodies existed in TG-treated cells, supporting that thapsigargin is a potent activator of apoptosis in the cells.

Key words: apoptosis, calcium, human hepatoma cells, thapsigargin, flow cytometry, electron microscope.

\section{INTRODUCTION}

Apoptosis is a common form of cell death in eukaryocytes and play an important

1 Dedicated to Professor Yao Zhen's 80th Birthday.

2 To whom all correspondence should be addressed. 
TG induces apoptosis in hepatoma cells

role in embryonic development and adult tissue regulation[i]. Like cell growth and differentiation, apoptosis is an active process which requires coordinated regulation of specific genes[2]. In addition, there is increasing evidence to suggest that apoptosis in most animal cells can be activated or suppressed by external signals[3]. As a member of second messengers, intracellular free calcium is considered to be important to cell growth, differentiation as well as apoptosis[4]. However, the precise mechanism by which $\mathrm{Ca}^{2+}$ signal regulates apoptosis is to be clarified.

Recently, we have found that thapsigargin (TG), an inhibitor of Ca-ATPase in surface of endoplasmic reticulum, produces a transient increase of intracellular $\mathrm{Ca}^{2+}$ in human hepatoma BEL- 7404 cells and disturbs the response of intracellular $\mathrm{Ca}^{2+}$ following the stimulation with epidermal growth factor, due to the depletion of intracellular $\mathrm{Ca}^{2+}$ storage in endoplasmic reticulum[5]. Therefore, in the present study, the effects of thapsigargin on apoptotic cell death in BEL-7404 cells were investigated by using flow cytometry and morphological analysis.

\section{MATERIALS AND METHODS}

\section{Cell culture}

Human hepatoma cell line BEL-7404 cells were grown in Dulbocco's modified Eagle's medium (DMEM, Gibco) supplemented with $13 \%$ fetal calf serum in $5 \% \mathrm{CO}_{2}$ incubator at $37^{\circ} \mathrm{C}$ and culture medium was changed every $48 \mathrm{~h}$. After the cells grew into semi-confluent, the cells were kept in the serum-free medium, and treated with TG (Sigma) at indicated concentration for certain period before assay.

\section{Transmission electronrnicroscopy}

BEL-7404 cells grown in monolayer culture were collected by trypsinizing. The cells were fixed in $5 \%$ glutaraldehyde, postfixed in $2 \% \mathrm{OsO}_{4}$, and embedded with Epom812. Ultrathin sections were cut and stained with uranyl acetate and lead citrate and viewed in a JEM100B electron microscope.

\section{Flow cytornetry}

After being trypsinized, the cells were centrifugated at $250 \times \mathrm{g}$ for $5 \mathrm{~min}$, and the cell pellet was resuspended in $1 \mathrm{ml}$ hypotonic fluorochrome solution (propidium iodide $50 \mu \mathrm{g} / \mathrm{ml}$ in $0.1 \%$ sodium citrate plus $0.1 \%$ Triton X-100, Sigma). The sample was kept at $4^{\circ} \mathrm{C}$ in dark overnight. The propidium iodide fluorescence of individual cells was measured by using a FACStar Plus flow cytometry (Becton and Dickinson). The cell cycle distributions were analyzed, and the cells with lower DNA contents than those in $\mathrm{G}_{1}$ phase cells were considered as apoptotic cells. Each value represented at least two separate experiments with more than 10,000 cells assayed.

\section{RESULTS AND DISCUSSION}

As shown in Fig 1, in the serum-free condition, TG (from $0.01 \mu \mathrm{M}$ to $1 \mu \mathrm{M}$ ) treatment for $48 \mathrm{~h}$ increased the rate of apoptotic cell death of BEL-7404 cells in a dose-dependent manner. Whereas in the presence of fetal calf serum (13\%), treatment with TG, even at $1 \mu \mathrm{M}$, did not produce the detectable increase in the rate of apoptosis. Furthermore, prolongation of the period of serum-free condition, from $24 \mathrm{~h}$ to $72 \mathrm{~h}$, enhanced the rate of apoptosis induced by TG $(0.1 \mu \mathrm{M}$ for $24 \mathrm{~h})$ from 
$6.01 \%$ to $20.83 \%$ of total assayed cells (Fig 2). But serum-starvation itself demonstrated rather weak effect on apoptosis in BEL-7404 cells. These results suggest that serum-starvation and TG treatment have additive effects on apoptotic cell death.

Fig 1. Dose-dependence of TG-induced apoptosis in BEL-7404 cells.

In the presence $(-\diamond)$ or absence $(-\diamond-)$ of fetal calf $\operatorname{serum}(13 \%)$ in the medium, the cells were treated with indicated concentrations of TG for $48 \mathrm{~h}$ and then stained with propidium iodide for flow cytometry analysis.
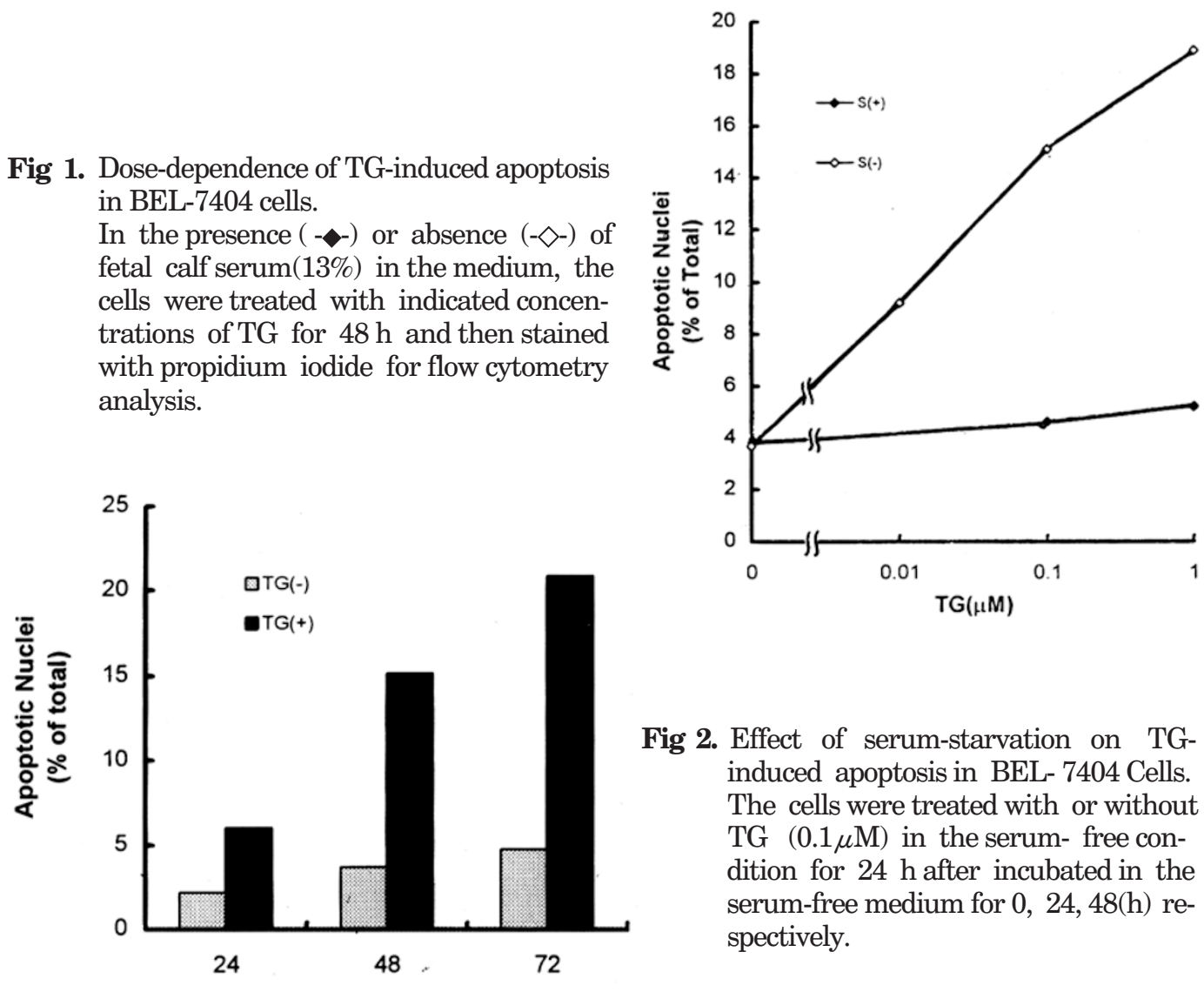

Time in serum-free medium (h)

Fig 2. Effect of serum-starvation on TGinduced apoptosis in BEL- 7404 Cells. The cells were treated with or without TG $(0.1 \mu \mathrm{M})$ in the serum- free condition for $24 \mathrm{~h}$ after incubated in the serum-free medium for $0,24,48(\mathrm{~h})$ respectively.

The ultrastructural features of the cells treated with TG were shown in Fig 3. In contrast to the control cells, the condensed and fragmented chromatin was observed in TG treated cells (Fig 3A and 3B), and the nuclear membrane as well as plasma membrane could keep intact for a certain period of time in TG-treated cells. In addition to the pycnotic nuclei, blebbing of apoptotic body containing organelles from the cell surface (Fig 3C) and appearance of apoptotic body containing fragmented chromatin in the cytoplasm can also be observed in TG treated cells (Fig 3D).

Cell death may occur by necrosis or through the specific process of apoptosis. Apoptosis, which is an active process triggered by internal or external signals, is morphologically characterized by condensation and fragmentation of chromatin, formation of apoptotic body; and existence of well-perserved plasma membranes. In TG-treated BEL-7404 hepatoma cells, typical morphological features of apoptosis 
TG induces apoptosis in hepatoma cells

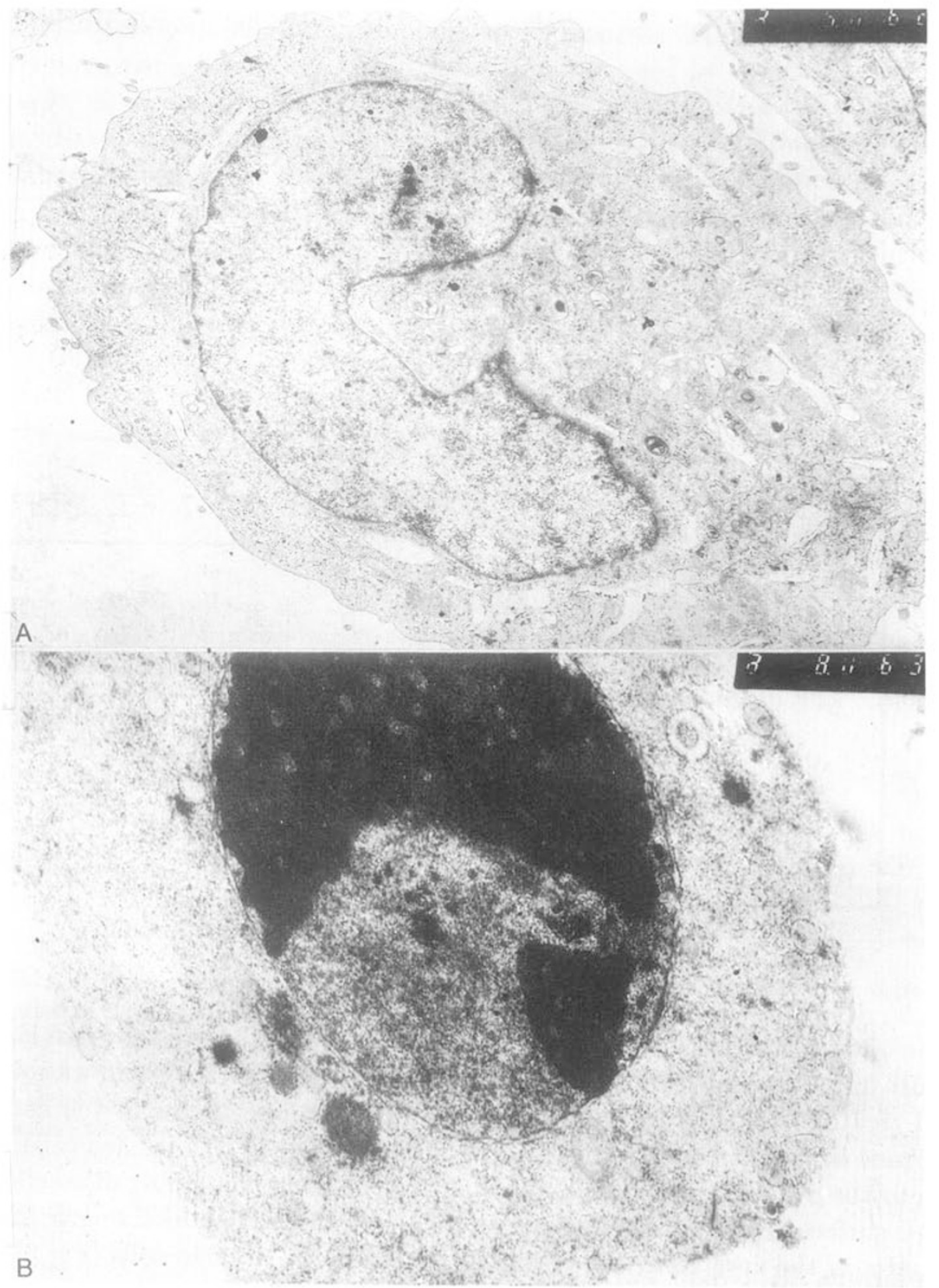

Fig 2. Ultrastructure of BEL-7404 cells treated with or without TG for $48 \mathrm{~h}$ in serum-free medium.

(A) Control. $(\times 5,000)$ (B) Treated with $0.1 \mu \mathrm{M}$ TG. $(\times 8,000)$ 
$\mathrm{Gu} \mathrm{J}$ et al.

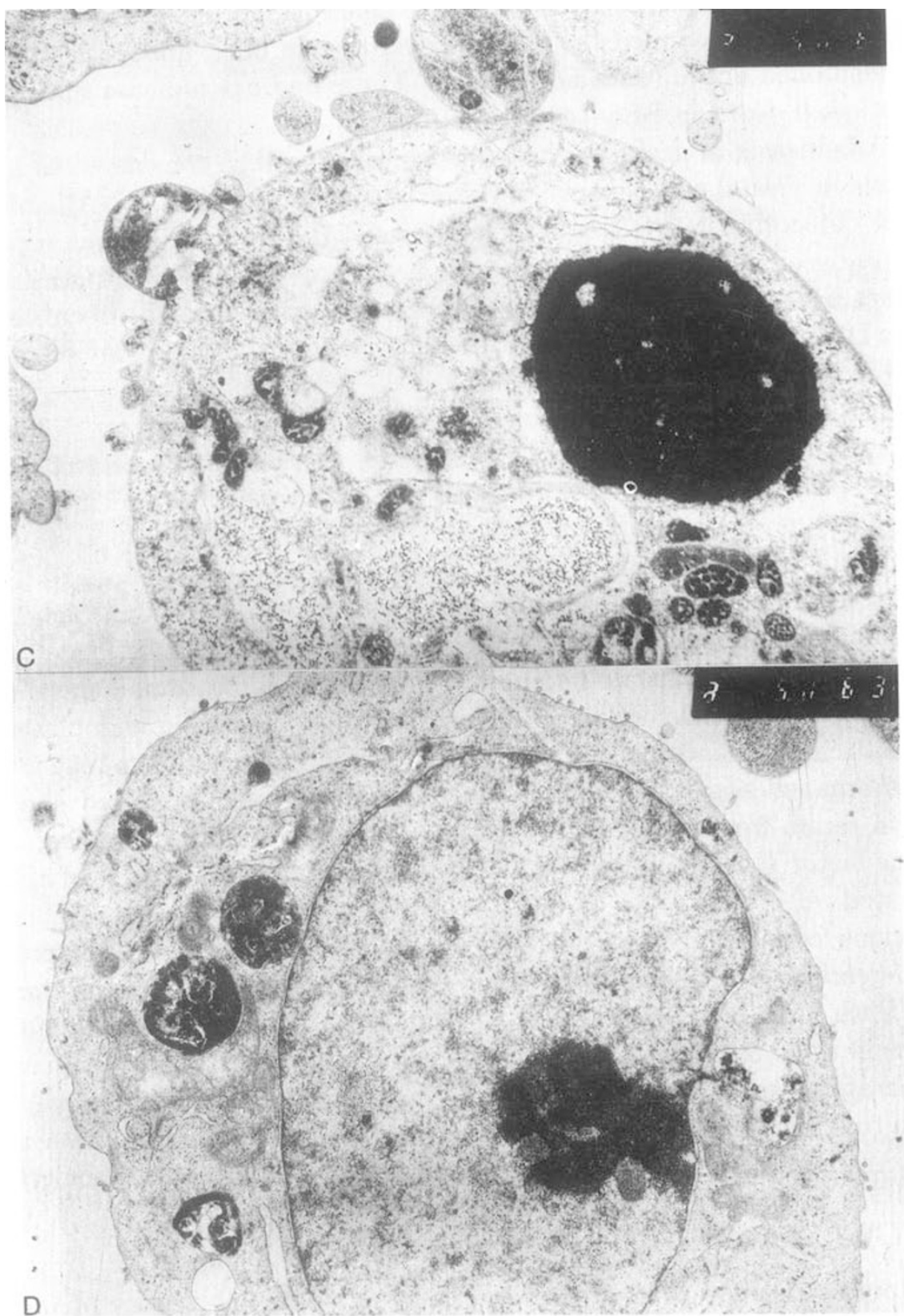

Fig 2. Ultrastructure of BEL-7404 cells treated with or without TG for $48 \mathrm{~h}$ in serum-free medium.

(C) Treated with $1 \mu \mathrm{M}$ TG. $(\times 5,000)$ (D) Treated with $1 \mu \mathrm{M}$ TG. $(\times 5,000)$ 
TG induces apoptosis in hepatoma cells

were observed by electron microscope and the increased rate of sub- $\mathrm{G}_{1}$ cells, with lower DNA content than that in $\mathrm{G}_{1}$ phase cells, was demonstrated by flow cytometric analysis. In addition, an assay of plasma membrane integrity showed more than $95 \%$ of cells excluded the charged dye, trypan blue, under the similar conditions mentioned above (data not shown). These findings indicate that TG induces apoptotic cell death in BEL-7404 cells.

DNA laddering in agarose gel electrophoresis has been considered as a marker of apoptosis in several cell systems. However, in our experiment, DNA ladder pattern was not detectable in TG-treated hepatoma BEL-7404 cells. It was reported that $\mathrm{TGF}_{\beta 1}$-induced apoptosis occurred in rat liver tissue without DNA laddering[6]. On the other hand, the Morris hepatoma cells undergoing ischemic necrosis showed a distinct DNA ladder pattern without demonstrating the morphology of apoptosis[7]. Therefore, our data presented here support the notion that DNA laddering may not be a sensitive and specific indicator of apoptosis in hepatocytes.

Alteration in intracellular $\mathrm{Ca}^{2+}$ homeostasis can be critically involved in apoptosis, and sustained elevation of cytosolic $\mathrm{Ca}^{2+}$ is capable of inducing apoptosis[4], although the precise mechanism by which calcium promotes apoptosis is unclear. However, the endogenous $\mathrm{Ca}^{2+} / \mathrm{Mg}^{2+}$ dependent endonuclease appears to be activated by the mobilization of cytosolic $\mathrm{Ca}^{2+}$ [8]. Alternatively, $\mathrm{Ca}^{2+}$ might activate $\mathrm{Ca}^{2+} /$ calmodulin-dependent kinase, leading to apoptosis[4]. TG, an inhibitor of $\mathrm{Ca}^{2+}$-ATPase in endoplasmic reticulum, produces an increase of intracellular $\mathrm{Ca}^{2+}$ in BEL-7404 cells[5]. Depletion of intracellular $\mathrm{Ca}^{2+}$ storage in endoplasmic reticulum results in the elevation of cytosolic $\mathrm{Ca}^{2+}$, and may cause the redistribution of $\mathrm{Ca} 2+$ in organelles, such as nucleus and mitochondria. TG-induced apoptosis occurred in serum-free condition, not in the presence of serum, suggesting that there are some factor(s) in serum, which act as the negative modulator(s) of apoptosis in TG-treated cells.

Previous focus of molecular oncology lay mainly in the control of cell proliferation and differentiation, however, there is now compelling evidence showing that the rate of cell death must be considered[9]. The induction of apoptosis is one of the major concerns in the recent development of therapeutic approach against cancer. TG, by inducing apoptosis of human cancer cells, may be considered as a novel potential agent in the treatment of cancer. Clarification of the biochemical pathways involved in the activation of apoptosis would lead to fundamental advances in cancer therapy.

\section{ACKNOWLEDGEMENTS}

The project is supported in part by Shanghai Joint Laboratory of Life Science Foundation. 


\section{REFERENCES}

[1] Ellis RE, Yuan J, Horvitz HR. Mechanisms and functions of cell death. Annun Rev. Cell Biol 1991; 7:663-98.

[2] Osborne BA, Schwartz LM. Essential genes that regulate apoptosis. Trends in Cell Biology 1994; 4:394-9.

[3] Collins MKL, Rivas AL. The control of apoptosis in mammalian cells. TIBS 1993; 18:307-9.

[4] Lee S, Christakos S, Small MB. Apoptosis and signal transduction: clues to a molecular mechanism. Current Opinion in Cell Biology 1993; 5:286-91.

[5] Fu T, Xu YH, Jiang WL, Zhang HY, Zhu PH, Wu J. EGF receptor-mediated intracellular calcium increase in human hepatoma BEL-7404 cells. Cell Research 1994; 4:145-53.

[6] Oberhammer F, Brusch W, Tiefenbacher R, Froschl G, Pavelke M, Purchio T, et al. Apoptosis is induced by transforming growth factor- $\beta 1$ within 5 hours in regressing liver without significant fragmentation of DNA. Hepatology 1993; 18:1238-46.

[7] Fukuda K, Kojiro M, Chiu JF. Demonstration of extensive chromatin cleavage in transplanted Morris hepatoma 7777 tissue :apoptosis or necrosis? American Journal of Pathology 1993; 142:935-46.

[8] Bellomo G, Perotti M, Taddei F, Mirabelli F, Finardi G, Nicotera P, et al. Tumor necrosis factor alpha induces apoptosis in mammary adenocarcinoma cells by an increase in intranuclear $\mathrm{Ca}^{2+}$ concentration and DNA fragmentation. Cancer Research 1992; 52:1342-6.

[9] Meeting report. Cell death in cancer and development: AACR special conference in cancer research. Cancer Research 1994; 54:2812-8.

Received 12-4-1995. Revised 8-5-1995. Accepted 12-5-1995. 